\title{
Retraction Note to: Correlation of hydromyelia with subarachnoid hemorrhage-related hydrocephalus: an experimental study
}

\author{
Anas Abdallah ${ }^{1}$
}

Published online: 13 November 2021

○) Springer-Verlag GmbH Germany, part of Springer Nature 2021

Retraction Note to: Neurosurgical Review (2021) 44:1437-1445

https://doi.org/10.1007/s10143-020-01330-2

The Editor-in-Chief, in consultation with the Springer Nature Research Integrity Group, has retracted this article because the author did not have approval from the animal ethics committee of Bezmialem Vakif University where this study was performed. Anas Abdallah does not agree with this retraction.
Publisher's note Springer Nature remains neutral with regard to jurisdictional claims in published maps and institutional affiliations.

The original article can be found online at https://doi.org/10.1007/ s10143-020-01330-2.

Anas Abdallah

abdallahanas@hotmail.com; dr.anasabdallah@gmail.com

1 Department of Neurosurgery, Bezmialem Vakif University, Adnan Menderes Bulvari, Vatan Street, 34093 Fatih, Istanbul, Turkey 